\title{
Incidence of Acute Coronary Syndrome Between Men and Women: Integrative Review
}

\begin{abstract}
Kaiomakx Renato Assunção Ribeiro'*, Thales Antônio Martins Soares², Rachel Iglesias Teodoro dos Santos $^{3}$, André Rodrigues dos Santos ${ }^{4}$, Lorena Suquyama Lelis ${ }^{5}$, Widney de Castro Baião ${ }^{6}$, Daniella Valença Daher $^{7}$, Edivalda Pereira de Abreu ${ }^{8}$ and Fernanda Alves Ferreira Gonçalves ${ }^{9}$

${ }^{1}$ Institute of Strategic Health Management of the Federal District-IGES-DF, Researcher the group and research, Network of Nursing Care for Critically ill patients -CNPq, Brazil
\end{abstract}

${ }^{2}$ Nursing School of the Federal University of Goiás-FEN-UFG, Brazil

${ }^{3,4}$ Institute of Strategic Health Management of the Federal District-IGES-DF, Brazil

5Superior School of Health Sciences of the Federal District-ESCS-DF, Brazil

${ }^{6,7}$ Instituto Hospital de Base do Distrito Federal-IHBDF, Brazil

${ }^{8}$ Hospital das Clinicas de Goiás-HCUFG, Brazil

${ }^{9}$ Federal University of Goiás-FEN-UFG, Coordinator of the research group Nursing Care Network for Critically ill patients - CNPq, Brazil

*Corresponding author: Kaiomakx Renato Assunção Ribeiro, Institute of Strategic Health Management of the Federal District-IGES-DF, Researcher the group and research, Network of Nursing Care for Critically ill patients -CNPq, Brazil.
Received Date: November 08, 2019

Published Date: January 17, 2020

\section{Abstract}

Objective: To analyze the difference between the male and female genders regarding the number of cases of acute coronary syndrome (ACS)/ acute myocardial infarction (AMI).

Method: This is an integrative literature review study, in which articles were searched in the following databases: MEDLINE, LILACS, SCIELO, BDENF. The articles were published between the years 2006 and 2018.

Results: Initially, 502 studies were found, 17 of which were selected to compose this research. Studies in general have pointed to a high incidence of ACS/AMI in males, however, a linear increase in the incidence of cardiovascular diseases in females has been observed in recent years. And that the factors associated with the appearance are hypertension, smoking, alcoholism, sedentary lifestyle and obesity, among others.

Conclusion: The incidence of patients with ACS/AMI every year has been a major challenge for health institutions and health professionals. The gender most affected by these diseases and the male gender, however, the increase in new cases in women has increased linearly in recent years.

Keywords: Myocardial infarction; Epidemiology; Coronary disease; Acute coronary syndrome

\section{Introduction}

Cardiovascular diseases (CVDs) are the main responsible for the increase in morbidity and mortality of most of the population. Among the CVD is the Acute Myocardial Infarction (AMI), the main cause of death in developed and developing countries, which corresponds to more than $30 \%$ of deaths in Brazil, which makes it considered an important indicator of quality standards of policies in collective health for being a disease with great impact $[1,2]$.
The diagnosis of AMI is confirmed by electrocardiogram (ECG) leading to AMI classification with supra-ST segment elevation (STEMI) and non-ST-segment elevation myocardial infarction (NSTEMI). These diagnostic methods can be identified by simple interpretation of this test.(1) This test is considered the quickest and easiest to identify or not AMI, and is described by protocols and guidelines such as the EKG-port time that should be performed 
within ten minutes of the patient's arrival at the hospital [3]. In 2009, the AMI was the third largest responsible cause of hospitalization in the Unified Health System (UHS). This represented a total of $10.2 \%$ of hospitalizations, a number that exceeds $25 \%$ when the population over 50 years of age is analyzed [4].

It is estimated that 635 thousand Americans will be hospitalized annually due to acute coronary syndrome. Regarding hospital mortality related to STEMI, there was a significant drop of $11.5 \%$ in 1990 to $8.0 \%$ in 2006 . This decline is related to advances in clinical pharmacotherapy and reperfusion strategies such as primary percutaneous coronary intervention (PCI), and to changes in patients regarding their demographic profile [5]. In Brazil, according to data from the Unified Health System and the Ministry of Health, there were 84,945 deaths from ischemic heart disease in 2005. In 2008, information systems recorded 518 hospitalizations for AMI in Rio Grande do Sul. In the United States, approximately 1.5 million patients each year develop AMI, of which $40 \%$ to $50 \%$ are accompanied by an increase in the ST segment. Between 25 and $30 \%$ of non-fatal AMI are not recognized by the patient and are discovered by routine ECG or post-mortem examination. The ECG associated with a good clinical history and physical examination is essential in the diagnosis of patients with chest pain and an advantageous resource, because it allows rapid and low-cost procurement [6].

It is worth mentioning that the death rates due to hospital and pre-hospital AMI are still significant, despite the decrease in the inhospital phase, especially the incidence of the disease analyzed in Brazilian metropolises, represents a high cost for the country [7]. Regarding the most prevalent risk factor in the development of AMI, Systemic Arterial Hypertension (SAH) stands out, besides being evidenced as a significant rate of hospital mortality in patients with definitive diagnosis [2]. As for the most affected gender, it is perceived in the studies that the male gender still represents in an expressive way, the most affected gender when compared to the female gender. Thus, this study aimed to analyze the difference between the male and female genders regarding the number of cases of Acute Coronary Syndrome (ACS)/AMI.

Describing these data may represent a warning to the representative health entities to intensify the strategies to combat, control and prevent CVDs, since this type of disease is responsible for a high mortality rate in the world every year. In addition, this study may favor the knowledge of health professionals about the theme, which may help in the individual guidance between genders, favoring decision making, and in the prevention of associated complications of CVDs.

\section{Method}

This is an integrative literature review, adopting the PICO search strategy, which represents an acronym for (P) Population or Patient, (I) Intervention, (C) Control or Comparison, (O) Outcomes. As a population, the patients who developed AMI were emphasized. The intervention (I) and the control/comparison (C) do not apply to this study. The expected outcome/Outcomes are the knowledge of the gender most affected by ACS/AMI as well as the knowledge of factors associated with CVDs development, in order to draw attention to these factors and encourage their prevention. The selected studies are characterized as observational, descriptive, analytical studies that addressed the ACS/AMI and analyzed the male and female genders and the factors related to their emergence.

This review followed 6 interrelated steps: establishment of hypothesis or guiding question, sampling or literature search, categorization of the study, evaluation of studies included in the review, interpretation of results, synthesis of knowledge or presentation of the review. The guiding question drawn from the PICO strategy focused on: What is the incidence of ACS/AMI between males and females described in the literature? Subsequently, a survey of articles was carried out between November 2017, using the following Health Sciences Descriptors (Decs): Myocardial infarction; Epidemiology; Coronary disease; Acute Coronary Syndrome. The descriptors were combined with each other using the Boolean operator "AND" to refine the search. The bibliographic survey was guided by the guiding question described above.

Thus, a survey of scientific publications available in the Latin American and Caribbean Literature in Health Sciences (LILACS), Medical Literature Analysis and Retrieval System Online (MEDLINE), Scientific Electronic Library Online (SciELO) and nursing database (BDenf) databases was conducted. Filters were used: articles available in full, publications from the period from 2008 to 2018 in Portuguese, English and/or Spanish. The inclusion criteria were studies available in full, observational, descriptive, analytical; published between 2006 and 2018, which addressed ACS/AMI in humans within the scope of clinical practice, in which the authors are health professionals (nurses, physicians, pharmacists and physiotherapists). However, to compose the results of this research, we used studies pulicado in the last 6 years (2012-2018). The exclusion criteria adopted were:

1) articles that did not address SCA/AMI,

2) articles published prior to the year 2012,

3) previous notes,

4) annals of events,

5) books or chapters, and

6) books. Articles with double publication or that were available in two or more databases were considered only once.

The results were then presented in tables in two tables, the first consisting of the identification of the articles represented by the letter "A" followed by an Arabic number (A1,A2-A17) successively, classification regarding the methodological design, the level of evidence to which each study refers and the degree of recommendation according to the Oxford classification (Table 1) [8-19]. The second table was complementary to the first, containing the title, the sample size of each study represented by the letter (n) and the population affected according to male (GM) and female (GF) (Table 2). 
Table 1: Classification of the studies included in this review according to the level of evidence and recommendation according to "Oxford Centre for Evidence-based Medicine", Brasília-DF, 2018.

\begin{tabular}{|c|c|c|c|}
\hline Articles & Method & Level & Grades of Recommendation \\
\hline $\mathrm{A} 1^{8}$ & Retrospective descriptive study & $2 \mathrm{C}$ & B \\
\hline $\mathrm{A} 2^{9}$ & Prospective observational study & $2 \mathrm{C}$ & B \\
\hline $\mathrm{A} 3^{10}$ & Prospective observational study & $2 \mathrm{C}$ & B \\
\hline $\mathrm{A} 4^{2}$ & Descriptive, retrospective study & $2 \mathrm{C}$ & B \\
\hline $\mathrm{A} 5^{5}$ & Retrospective descriptive study & $2 \mathrm{C}$ & B \\
\hline $\mathrm{A} 6^{11}$ & Descriptive, longitudinal study & $2 \mathrm{C}$ & B \\
\hline $\mathrm{A} 7^{12}$ & Prospective observational study & $2 \mathrm{C}$ & B \\
\hline $\mathrm{A} 8^{13}$ & Cross-sectional descriptive study & $2 \mathrm{C}$ & B \\
\hline $\mathrm{A} 9^{14}$ & Retrospective cohort study & $2 \mathrm{~B}$ & B \\
\hline $\mathrm{A} 10^{15}$ & Observational study, case series type & $1 \mathrm{C}$ & A \\
\hline $\mathrm{A} 11^{16}$ & Retrospective descriptive study & $2 \mathrm{C}$ & B \\
\hline $\mathrm{A} 12^{1}$ & Retrospective descriptive study & $2 \mathrm{C}$ & B \\
\hline${\mathrm{A} 13^{4}}^{4}$ & Prospective study & $2 \mathrm{C}$ & B \\
\hline $\mathrm{A} 14^{17}$ & Descriptive and exploratory study & $2 \mathrm{C}$ & B \\
\hline $\mathrm{A} 15^{18}$ & Retrospective descriptive study & $2 \mathrm{C}$ & B \\
\hline $\mathrm{A} 16^{19}$ & Prospective cross-sectional study & $2 \mathrm{C}$ & B \\
\hline $\mathrm{A} 17^{3}$ & Descriptive prevalence study & $2 \mathrm{C}$ & B \\
\hline
\end{tabular}

Source: Authors 2018

Table 2: Characteristics between genders of patients with ACS/AMI according to the publications included in this review. Brasília-DF, 2018.

\begin{tabular}{|c|c|c|c|c|}
\hline Articles & Title & $\mathbf{N}$ & GF (\%) & GM (\%) \\
\hline $\mathrm{A} 1^{8}$ & Risk factors for first-time acute myocardial infarction patients in Trinidad & 252 & $113(45 \%)$ & $138(55 \%)$ \\
\hline $\mathrm{A} 2^{9}$ & $\begin{array}{c}\text { Gender gap in medical care in networks for acute myocardial infarction with ST segment } \\
\text { elevation: findings of the Catalan network Codi Infart }\end{array}$ & 4380 & $961(21.9 \%)$ & $3419(78,1 \%)$ \\
\hline $\mathrm{A} 3^{10}$ & $\begin{array}{l}\text { Epidemiological Profile and Quality Indicators in Patients with Acute Coronary Syndrome in the } \\
\text { North Region of Minas Gerais-Minas Gerais Project Telecardio } 2\end{array}$ & 277 & $95(34,3 \%)$ & $182(65,7 \%)$ \\
\hline $\mathrm{A} 4^{2}$ & Profile of the population affected by acute myocardial infarction. & 106 & $36(34 \%)$ & $70(66 \%)$ \\
\hline $\mathrm{A} 5^{5}$ & $\begin{array}{l}\text { Clinical and angiographic profile of young patients submitted to primary percutaneous coronary } \\
\text { intervention }\end{array}$ & 489 & $151(30,9 \%)$ & $338(69,1)$ \\
\hline $\mathrm{A} 6^{11}$ & $\begin{array}{c}\text { Pre-hospital indicators in the evaluation of the quality of care to patients with acute coronary } \\
\text { syndrome }\end{array}$ & 94 & $45(47,9 \%)$ & $49(52,1 \%)$ \\
\hline $\mathrm{A} 7^{12}$ & $\begin{array}{l}\text { Clinical characteristics and long-term evolution of young patients with acute coronary syndrome } \\
\text { in Brazil }\end{array}$ & 268 & $115(43 \%)$ & $153(57 \%)$ \\
\hline $\mathrm{A} 8^{13}$ & $\begin{array}{c}\text { Evaluation of the waiting time of the initial electrocardiogram in patients with Acute Coronary } \\
\text { Syndrome }\end{array}$ & 116 & $53(45,7 \%)$ & $63(54,3 \%)$ \\
\hline $\mathrm{A} 9^{14}$ & $\begin{array}{l}\text { Epidemiology of coronary artery bypass grafting at the Hospital Beneficência Portuguesa, São } \\
\text { Paulo }\end{array}$ & 3011 & $906(30,1 \%)$ & $2105(69,9 \%)$ \\
\hline $\mathrm{A} 10^{15}$ & $\begin{array}{c}\text { Comparison of the Clinical-Epidemiological Profile between Men and Women in Acute Coronary } \\
\text { Syndrome }\end{array}$ & 927 & $556(60 \%)$ & $371(40 \%)$ \\
\hline $\mathrm{A} 11^{16}$ & Clinical and epidemiological profile of patients with acute coronary syndrome & 150 & $52(34,7 \%)$ & $98(65,3 \%)$ \\
\hline $\mathrm{A} 12^{1}$ & $\begin{array}{l}\text { Profile of patients admitted with Acute Myocardial Infarction at Hospital de Urgência de Teresi- } \\
\text { na-PI }\end{array}$ & 240 & $105(43,8 \%)$ & $135(56,2 \%)$ \\
\hline${\mathrm{A} 13^{4}}^{4}$ & Behavior of Acute Coronary Syndrome. Results of a Brazilian Registration & 2693 & $864(32,1 \%)$ & $1829(67,9 \%)$ \\
\hline $\mathrm{A} 14^{17}$ & Clinical evolution of inpatients due to the first episode of acute coronary syndrome & 140 & $34(24,3 \%)$ & $106(75,7 \%)$ \\
\hline $\mathrm{A} 15^{18}$ & $\begin{array}{c}\text { Risk Factors Associated with Death by Acute Myocardial Infarction in the Intensive Care Unit of a } \\
\text { Hospital do Sul de Minas Gerais }\end{array}$ & 187 & $56(30 \%)$ & $131(70 \%)$ \\
\hline $\mathrm{A} 16^{19}$ & Time of arrival of the patient with acute myocardial infarction in the emergency unit & 52 & $12(23,1 \%)$ & $40(76,9 \%)$ \\
\hline \multirow[t]{2}{*}{$\mathrm{A} 17^{3}$} & Study on the profile of patients with Acute Coronary Syndrome & 145 & $53(36,6 \%)$ & $92(63,4 \%)$ \\
\hline & Articles N & 13526 & $4207(31,1 \%)$ & $9319(68,9 \%)$ \\
\hline
\end{tabular}

\section{Source: Authors, 2018}

$\mathrm{n}=$ Participants affected by ischemic heart disease / Acute Coronary Syndromes in each study

$\mathrm{N}=$ Total number of patients affected by ischemic heart disease / Acute Coronary Syndromes in the 18 studies included.

GF\% $=$ Percentage of female patients

$\mathrm{GM} \%=$ Percentage of male patients 


\section{Results}

Initially, 502 articles were searched using the combined descriptors. After the use of filters (full text available, publications between 2008 and 2018), 148 articles remained. After the analytical reading (title and abstract), 43 articles remained. After the complete reading of the articles, 17 articles were selected to compose the final sample of the research, which were distributed and synthesized in (Tables 1\&2). This section presents the analysis of the results of this study, which aimed to verify which incidence of coronary syndromes between men and women. With regard to the level of evidence and the degree of recommendation of the studies, 15 articles (88.24\%) presented as NE 2C; 1 study (5.88\%) with NE $2 \mathrm{~B}$, masters with degree of recommendation "B" in the Oxford scale, and 1 study (5.88\%) with NE $1 \mathrm{C}$ with degree of recommendation "A" (Table 1).

The 17 studies analyzed resulted in 13526 patients affected by ACS/AMS. Of this total, 4207 (31.1\%) patients were female, compared to 9319 (68.9\%) male patients. Regarding the individual analysis of each study, the 17 articles (100\%) presented a higher incidence of ACS/AMI in males. However, it was noticed that there was a considerable increase in the incidence of ACS/AMI in female patients in recent years.

\section{Discussion}

A study published in 2014 comparing the clinical profile between men and women with AMI showed that the overall mortality coefficient is higher among men than among women in all the years considered. However, the SAH variable, when compared to its frequency between genders, showed a higher incidence among women $(p=0.001)$, while smoking and alcoholism were more frequent in men ( $p=0.01$ ) [15]. With regard to risk factors, studies have shown that there are several risk factors associated with AMI, including: marital status, retirement, family history of coronary insufficiency, history of SAH and Diabetes Mellitus (DM), smoking, physical activity, LDL-cholesterol, HDL-cholesterol, glucose, Body Mass Index (BMI), among others [1-5,11-13,15,16,18-20]. These factors are always more frequent in males, but the increase in these factors in females in recent years has been significant.

Another study whose sample consisted of 50 patients demonstrated that $32 \%$ were smokers, with non-smokers prevailing, and many left the cigarette after being affected by acute myocardial infarction. And in relation to changes in cholesterol levels, $46 \%$ were at the desirable level of less than $200 \mathrm{md} / \mathrm{l}$, but very close to this number and $44 \%$ with cholesterol levels between 200-240mg/dl [21]. Thus, in both studies, increased cholesterol and smoking are directly related to the number of cases of AMI. These factors, among others, are the main responsible for the increase in hospital morbidity due to AMI. And that a large part of the target population demonstrates knowledge of the factors that trigger this pathology, but show little importance due to not having witnessed it. The high rate of deaths from AMI in Brazil could be much lower if preventive and health education strategies were more emphasized from childhood, inserted in the school curriculum along with physical education, emphasize the signs and symptoms during a routine consultation.

The study by Feijó et al. [22] demonstrated significant relevance in the influence of a genetic factor/family history when analyzing the pathophysiology of AMI and its possible predisposing factors in individuals under 40 years of age. With regard to hospitalizations for treatment by AMI, a study conducted in 2012 with evaluation of 145 medical records of patients who developed AMI showed that as for the type of acute ischemic syndrome, 53.10\% presented AMI with STEMI, 37.93\% presented AMI NSTEMI, 0.69\% presented unstable angina and $6.21 \%$ did not contain the data. Among the patients who underwent thrombolysis $(n=52), 84.62 \%$ had indication for therapy [3].

An analysis of the data collection from a study conducted between 2002 and 2003 showed that age above 60 years is a factor linked to hospitalization rate, an indicator of patient severity and an important predictor of death, with a clear correlation between age and probability of death [23]. Another study conducted in 2009 with 64 patients showed that $54.7 \%$ of the patients evaluated had dyslipidemia, $93.8 \%$ were hypertensive, $26.6 \%$ smokers, $37.5 \%$ diabetics and $67.2 \%$ were sedentary. In both cases the disease that motivated the hospitalization was ACS [24].

Thus, the most effective way to reduce the impact of CVDs, at the population level, is the development of prevention actions and treatment of their related factors. The multidisciplinary team should know the risk factors involved in triggering acute coronary syndromes more present in its area of action. Regarding the initial treatment of ACS, a study conducted in 2005 with 3,600 patients verified the low use of the main medications in the studied population, both on arrival at the hospital and on discharge. At admission, the use occurred in only $26.2 \%$ of patients, betablockers in $14 \%$, statins at $9 \%$ and angiotensin-converting enzyme inhibitors at $29.9 \%$, while the combined use of aspirin, betablockers and statins were recorded in only $4.5 \%$ of patients [25].

The initial treatment performed in 50 patients (32\%) was venous thrombolysis, and ten of them (20\%), without recanalization criteria, were referred for rescue angioplasty. Forty-one patients (26\%) underwent primary angioplasty, and in about $40 \%$ of them the procedures were performed with a balloon door time of less than 90 minutes. The majority of patients (42\%) were maintained in clinical treatment, although they arrived at the emergency room in time to perform some type of reperfusion [25].

Regarding the therapeutic combination between and the power of currently recommended therapies such as thrombolysis, antiplatelet agents, beta-blockers, angiotensin-converting enzyme inhibitors and angioplasty in the number of lives saved, it is not clear [26]. Another study carried out in 2007 [27] with 611 randomized patients showed that 483 patients were monitored for quality of life evaluations and demographic profile questionnaire. These patients formed the following therapeutic groups: coronary artery bypass grafting 161 patients (33.3\%), percutaneous coronary 
angioplasty 166 patients (34.3\%) and medical treatment 153 patients (32.4\%) being monitored periodically. In the study it was possible to verify that the patients of the three therapeutic options were similar when related to clinical conditions, angiography, use of medications, laboratory tests, among others. Of the patients in follow-up, $86 \%$ presented, at the admission of the study, angina symptoms class II or III; 34\% reported the occurrence of previous myocardial infarction; $32 \%$ were smokers.

All patients received specific medications for cardiac involvement and other comorbidities. Regarding the clinical treatment after four years of follow-up, of the 153 patients referred for clinical treatment, 12 (7.7\%) were victims of acute myocardial infarction, 24 (15.3\%) were submitted to coronary artery bypass grafting surgery and 19 (12.1\%) died. In addition, five patients (3.1\%) suffered an episode of stroke and 40 (25.6\%) reported symptoms of angina pectoris [27]. In both studies it was noticed that the treatment related to AMI is varied and dependent on the clinical situation and diagnosis of the affected patient. The abandonment of practices considered as risk factors are relevant with regard to the ease and effectiveness of the proposed treatment, reducing mortality. With regard to the infarctomy/ aneurysm procedure associated or not with coronary artery bypass grafting, little evidence was found on the subject. Although CVD have several risk factors for their involvement, there are not many studies that address the theme, from the perspective of male and female genders, their spatial distribution and their interactions with stressors, socioeconomic and environmental factors.

\section{Conclusion}

The present study showed a higher prevalence of cases of CVD/ ACS/AMI in male patients. However, the number of cases of heart disease described in the literature in female patients, also draw the attention of professionals and authorities in the area of health. The results also suggest the importance of controlling and preventing risk factors associated with CVD, such as hypertension, smoking, diabetes mellitus, obesity, dyslipidemia, among others. Due to the scarcity of high-level studies of evidence that evaluate the risk factors, which characterizes a limitation of this study, we suggest new studies with more representative samples. However, the results, although limited, already reveal the need to seek planning of interventions to promote the health of the population, aimed at the prevention of risk factors, aiming at the prevention of heart disease, thus ensuring greater survival and mortality reduction.

\section{Acknowledgement}

None.

\section{Conflict of interest}

No Conflict of interest.

\section{References}

1. Jesus AV, Campelo V, Silva MJS (2013) Profile of patients admitted with Acute Myocardial Infarction in Hospital de Urgência de Teresina-PI. Rev Interd 6(1): 25-33.
2. Araújo IFM, Santos ISC, Longuiniere La ACF, Valença Neto PF, Franklin TA (2016) Profile of the population affected by acute myocardial infarction. Rev Nur UFPE on line 10(7): 2302-2309.

3. Torres GKV, Marques IR (2012) Study on the profile of patients with Acute Coronary Syndrome. Rev Sickbay UNISA 13(1): 21-26.

4. Piegas LS, Avezum A, Guimarães HP, Muniz AJ, Reis HJL, et al. (2013) Comportamento da Síndrome Coronariana Aguda. Results of a Brazilian Register. Arch Bras Cardiol 100(6): 502-510.

5. Andrade PB, Rinaldi FS, Bienert IRC, Barbosa RA, Bergonso MH, et al. (2015) Clinical and angiographic profile of young patients submitted to primary percutaneous coronary intervention. Rev Bras Cardiol Invasive 23(2): 91-95.

6. Damasceno CA, Queiroz TL, Santos CAST, Mussi FC (2012) Factors associated with the decision to seek health care in myocardial infarction: differences between genders. Rev Esc Enferm USP 46(6): 1362-1370.

7. Soares T, Souza EN, Moraes MA, Azzolin K (2009) Porta-Electrocardiogram time (ECG): an indicator of efficacy in the treatment of acute myocardial infarction. Rev Gaúcha Enferm 30(1): 120-126.

8. Bahall M, Seemungal T, Legall G (2018) Risk factors for first-time acute myocardial infarction patients in Trinidad. BMC Public Health 18(1): 161.

9. Fernández Rodríguez D, Regueiro A, Cevallos J, Bosch X, Freixa X, et al. (2017) Gender gap in medical care in acute myocardial infarction networks with ST segment elevation: findings of the Catalan network Codi Infart. Med Intensiva 41(2):70-77.

10. Marino BCA, Marcolino MS, Reis Júnior RS, França ALN, Passos PFO, et al. (2016) Epidemiological Profile and Quality Indicators in Patients with Acute Coronary Syndrome in the North Region of Minas Gerais-Project Minas Telecardio 2 Project. Arch Bras Cardiol 107(2): 106-115.

11. Maier GSO, Martins EAP, Dellaroza MSG (2015) Pre-hospital indicators in the evaluation of the quality of care to patients with acute coronary syndrome. Rev Gaúcha Enferm 36(3): 49-55.

12. Soeiro AM, Fernandes FL, Soeiro MC, Serrano Jr CV, Oliveira Jr MT (2015) Clinical characteristics and long-term evolution of young patients with acute coronary syndrome in Brazil. Einstein 13(3): 370-375.

13. Andrade KBS, Pinheiro APB, Bessa ATT, Paes GO, Stipp MAC (2015) Evaluation of the waiting time of the initial electrocardiogram in patients with Acute Coronary Syndrome. Rev nur UERJ 23(4): 443-448.

14. Sousa AG, Fichino MZS, Silva GS, Bastos FCC, Piotto RF (2015) Epidemiology of coronary artery bypass grafting at the Hospital Beneficência Portuguesa, São Paulo. Rev Bras Cir Cardiovasc 30(1): 3339.

15. Almeida MCA, Montenegro CEL, Sarteschi C, Montenegro GL, Montenegro PBR, et al. (2014) Comparison of the Clinical-Epidemiological Profile between Men and Women in Acute Coronary Syndrome. Rev Bras Cardiol 27(6): 423-429.

16. Araújo DF, Araújo ERM, Silva MRV, Silva NC, Guimarães MSO, et al. (2014) Clinical and epidemiological profile of patients with acute coronary syndrome. Rev Sickbay UFPI 3(2): 78-84.

17. Gil GP, Dessotte CAM, Schmidt A, Rossi LA, Dantas RAS (2012) Clinical evolution of hospitalized patients due to the first episode of acute coronary syndrome. Rev Latino Am Nursing 20(5): 830-837.

18. Lopes GF, Duca TA, Buissa T, Yano WK, Baracho NCV (2012) Risk factors associated with death by acute myocardial infarction in the intensive care unit of a hospital in southern Minas Gerais. Ciências em Saúde Journal 2(1): 1-13.

19. Bastos AS, Beccaria LM, Contrin LM, Cesarino, CB (2012) Time of arrival of the patient with acute myocardial infarction in the emergency unit. Rev Bras Cir Cardiovasc.

20. Ribeiro BGA, Martins JT, Bobroff MCC, Montezeli JH, Gomes (2013) Epidemiological profile of patients with cardiovascular disorders treated in the emergency room of a university hospital. Revista de Enfermagem e Atenção à Saúde 2(3): 32-41. 
21. Jaconodino CB, Amestoy SC, Thofehrn MB (2007) Patients knowledge about risk factors related to cardiovascular diseases. Cogitare Enfermagem 12(4): 466-471.

22. Feijó IP, Schmidt MM, David RB, Martins JMP, Schmidt KE, et al. (2015) Clinical profile and results of primary percutaneous coronary intervention in young patients. Rev Bras Cardiol Invasive 23(1): 48-51.

23. Evangelist PA, Barreto SM, War HL (2008) Access to hospitalization and factors associated with hospital death due to ischemic heart diseases in SUS. Arch Bras Cardiol 90(2): 130-138.

24. Pena FM, Peixoto RS, Soares JS, Pires Júnior HR, Pena GSA, et al. (2009) Clinical and angiographic profile of elderly patients with acute coronary syndrome admitted to a tertiary hospital. Rev SOCERJ 22(3): 176-180.
25. Santos ES, Minuzzo L, Pereira MP, Castillo MTC, Palácio MAG, et al. (2006) Registration of Acute Coronary Syndrome in a Cardiology Emergency Center. Arch Bras Cardiol 87: 597-602.

26. Baena CP, Olandoski M, Luhm KR, Costantini CO, Guarita Souza LC (2012) Acute Myocardial Infarction Mortality Trend in Curitiba (PR) from 1998 to 2009. Arch Bras Cardiol 98(3): 211-217.

27. Takiuti ME, Hueb W, Hiscock SB, Nogueira CRSR, Girardi P, et al. (2007) Quality of life after coronary artery bypass grafting, angioplasty or clinical treatment. Arquivos Brasileiros de Cardiologia 88(5): 537-544. 